\title{
Application of $B_{12} N_{12}$ and $B_{12} P_{12}$ as two fullerene-like semiconductors for adsorption of halomethane: density functional theory study
}

\section{(c) Ali Shokuhi Rad}

Department of Chemical Engineering, Qaemshahr Branch, Islamic Azad University, Qaemshahr, Iran

E-mail: a.shokuhi@gmail.com, a.shokuhi@qaemshahriau.ac.ir

\section{(Получена 3 фревраля 2016 г. Принята к печати 8 июня 2016 г.)}

We examined and discussed the interaction of two halomethanes (mono-chloromethane (MCM), and monofluoromethane (MFM)) with $\mathrm{B}_{12} \mathrm{~N}_{12}$ and $\mathrm{B}_{12} \mathrm{P}_{12}$ fullerene-like semiconductors based on density functional theory (DFT). We calculated adsorption energies and followed the changes in the electronic structure of semiconductors upon adsorption of MCM and MFM. We found that the adsorption on the $\mathrm{B}_{12} \mathrm{~N}_{12}$ nano-cluster is energetically more favorable compared to $\mathrm{B}_{12} \mathrm{P}_{12}$ nano-cluster. Also for both systems we found higher values of adsorption energy for MFM than for MCM. We found that upon adsorption of above-mentioned species on these two fullerene-like semiconductors, the HOMO-LUMO distributions and also the gap energy for each system did not change significantly, which correspond to the physisorption process. As a result, $\mathrm{B}_{12} \mathrm{~N}_{12}$ is a more appropriate nano-cluster to be used as a selective sensor for halomethanes, especially for MFM.

DOI: 10.21883/FTP.2017.01.44009.8191 